\title{
Characterization of anthropogenic impacts in a large urban center by examining the spatial distribution of halogenated flame retardants
}

\author{
Yan-Li Wei ${ }^{a, c}$, Lian-Jun Bao ${ }^{\text {b,* }}$, Chen-Chou Wu ${ }^{a, c}$ and Eddy Y. Zeng ${ }^{a, b}$ \\ ${ }^{a}$ State Key Laboratory of Organic Geochemistry, Guangzhou Institute of Geochemistry, \\ Chinese Academy of Sciences, Guangzhou 510640, China \\ ${ }^{\mathrm{b}}$ School of Environment, Guangzhou Key Laboratory of Environmental Exposure and Health, \\ and Guangdong Key Laboratory of Environmental Pollution and Health, Jinan University,
} Guangzhou 510632, China

${ }^{\mathrm{c}}$ University of Chinese Academy of Sciences, Beijing 100049, China

\begin{abstract}
Anthropogenic impacts have continuously intensified in mega urban centers with increasing urbanization and growing population. The spatial distribution pattern of such impacts can be assessed with soil halogenated flame retardants (HFRs) as HFRs are mostly derived from the production and use of various consumer products. In the present study, soil samples were collected from the Pearl River Delta (PRD), a large urbanized region in southern China, and its surrounding areas and analyzed for a group of HFRs, i.e., polybrominated diphenyl ethers (PBDEs), decabromodiphenyl ethane, bis(hexachlorocyclopentadieno)cyclooctane (DP) and hexabromobenzene. The sum concentrations of HFRs and PBDEs were in the ranges of 0.66-6500 and 0.37-5700 (mean: 290 and 250) $\mathrm{ng} \mathrm{g}^{-1}$ dry weight, respectively, around the middle level of the global range.

*Corresponding author e-mail: blj727722@163.com.
\end{abstract}


BDE-209 was the predominant compound likely due to the huge amounts of usage and its persistence. The concentrations of HFRs were greater in the land-use types of residency, industry and landfill than in agriculture, forestry and drinking water source, and were also greater in the central PRD than in its surrounding areas. The concentrations of HFRs were moderately significantly $\left(r^{2}=0.32-0.57 ; p<0.05\right)$ correlated with urbanization levels, population densities and gross domestic productions in fifteen administrative districts. The spatial distribution of DP isomers appeared to be stereoselective as indicated by the similarity in the spatial patterns for the ratio of anti-DP versus the sum of DP isomers $\left(f_{\text {anti-DP }}\right)$ and DP concentrations. Finally, the concentrations of HFRs sharply decreased with increasing distance from an e-waste recycling site, indicating that e-waste derived HFRs largely remained in local soil.

Keywords: Urbanization; Anthropogenic impact; Halogenated flame retardant; Pearl River Delta; Soil

"Capsule": The anthropogenic impacts in a large urban center were examined by the spatial distribution of soil halogenated flame retardants. 


\section{Introduction}

Urbanization is an essentially irreversible process accompanied with industrialization that spurs the migration of rural residents to urban centers (Engelke, 2012). As a consequence, large urban centers have become sources of anthropogenic impacts on the environment. This trend is expected to continue, particularly in developing countries, as the level of urbanization in these countries remains relatively low as compared to developed countries. Urbanization has created a series of pollution issues, exerting long-term stress to the health of the eco-environment and human beings (Chen, 2007; Lin et al., 2014; Szolnoki et al., 2013). The imbalance of social and economic development, however, may have resulted in substantial disparity in terms of the spatial distribution of environmental contamination.

The situation in China, the largest emerging economy in the world, is quite alarming, as the urbanization process is still underway at a fast pace. One source estimated that the urbanization level rose from $19.4 \%$ in 1980 to $50 \%$ in 2010 (China Statistical Yearbook, 2011). The rising standard of living, largely thanks to the rapid economic growth in the last three decades, has created strong demand for a variety of consumer products, e.g., textiles, electronics, thermoplastics, and building materials. For example, the outputs of washing machines, refrigerators, color television sets and air-conditioners had been escalating since 1978, when the Reform and Open Policy was first implemented (Fig. S1 of the Supplementary Data; "S" represents figures and tables in the Supplementary Data thereafter). Accompanied with this production surge, the global demand for halogenated flame retardants (HFRs) used to reduce the flammability in consumer products has increased by $4.6 \%$ per year and projected to reach 2.8 million metric tons in 2018 (http://www.marketresearch.com/Freedonia-Group-Inc-v1247/Flame-Retardants-8783038/). Because HFRs may be released to the environment during the manufacture and use of HFRs- 
containing commercial products (Alaee et al., 2003), their residual levels in the environment may be a good indicator of industrial output and human population.

The major component of HFRs, polybrominated diphenyl ethers (PBDEs), have been gradually banned or restricted for use in many countries, e.g., Deca-BDE was banned in Europe in 2008 (Law et al., 2008), Penta-BDE and Octa-BDE were phased out in USA in 2008 (Ward et al., 2008), while they were also banned in China in 2007 (Ding et al., 2016). Alternative novel HFRs including decabromodiphenyl ethane (DBDPE), bis(hexachlorocyclopentadieno)cyclooctane (DP) and hexabromobenzene (HBB) that meet the fire and safety regulations were introduced to replace PBDEs (Covaci et al., 2011; Sverko et al., 2011). Due to their persistence, bioaccumulation and biomagnification, PBDEs and novel HFRs may co-exist in the environment and pose a great threat to human health (Du et al., 2016; Law et al., 2008).

China is one of the most rapidly expanding HFR markets worldwide (http://www.marketresearch.com/Freedonia-Group-Inc-v1247/Flame-Retardants-8783038/), while the Pearl River Delta (PRD) located in southern China (Fig. 1) is an important manufacturing base of electronic/electrical products, textiles and building materials in the world. In addition, Qingyuan located in north of Guangzhou, the center of the PRD (Fig. S2), houses a large number of e-waste recycling facilities. Approximately 145 million pieces of obsolete electronic/electrical devices were processed in Qingyuan using mostly primitive techniques in 2002 (Martin et al., 2004). Therefore, it is not unexpected that samples of air, dust, sediment and birds collected from the PRD and surrounding areas contained high levels of HFRs (Li et al., 2014; Luo et al., 2014; Luo et al., 2009b; Peng et al., 2015; Shi et al., 2009; Sun et al., 2014; Yu et al., 2014). These previous findings hinted the feasibility of utilizing HFRs to assess anthropogenic impacts on a regional scale in the PRD. 
To this end, the present study was designed to determine the spatial pattern of HFRs in the PRD and its surrounding regions. Regional socioeconomic factors, such as population density, gross domestic production (GDP) and urbanization level, were also examined. Finally, concentrations of HFRs discharging from e-waste recycling site were compared with those at its surrounding areas to figure out the transport potential of derived HFRs from ewaste dismantling activities.

\section{Materials and methods}

\subsection{Materials}

Twenty-five target BDE congeners, including BDE-15, -17, -28, -47, -66, -71, -77, -85, $99,-100,-126,-138,-153,-154,-166,-181,-183,-190,-196,-203,-204,-206,-207,-208$ and -209, and DP were purchased from AccuStandard (New Haven, CT, USA). Two other target standards, i.e., DBDPE and HBB, were obtained from Cambridge Isotope Laboratories (Andover, MA, USA) and Wellington Laboratories (Guelph, ON, Canada), respectively. The surrogate standards BDE-51, BDE-115 and ${ }^{13}$ C-BDE-209 and internal standards BDE-69,

${ }^{13} \mathrm{C}-\mathrm{PCB}-208$ and ${ }^{13} \mathrm{C}-\mathrm{BDE}-139$ were supplied by Cambridge Isotope Laboratories. Hexane and dichloromethane of HPLC grade were acquired from Honeywell (Morristown, NJ, USA). In addition, acetone of analytical grade was obtained from Chemical Reagent Factory (Tianjin, China) and redistilled prior to use. Copper sheets were activated with diluted $\mathrm{HCl}$, and washed with distilled water and acetone sequentially.

\subsection{Sample design and sample collection}

Two hundred and twenty-nine soil samples were collected from the PRD and surrounding areas, southern China between December 2009 and March 2010 (Wei et al., 2014b). The sampling region is divided into six land-use types, i.e., residency, industry, 
landfill, agriculture, forestry and drinking water source (Fig. 1). In addition, fifteen administrative districts within the sampling region are divided into four groups, e.g., the central PRD (Shenzhen, Dongguan, Guangzhou, Zhuhai, Zhongshan and Foshan), the PRD's periphery (Zhaoqing, Jiangmen, Qingyuan and Huizhou), the East (Shaoguan, Heyuan and Shanwei) and West (Yangjiang and Yunfu) regions (Fig. 1), in an attempt to elucidate the spatial patterns of soil HFRs contamination.

\subsection{Sample extraction and instrument analysis}

Each freeze-dried soil sample ( 20 g) was Soxhlet-extracted with $170 \mathrm{~mL}$ of hexane:acetone:dichloromethane mixture (2:1:2 in volume) after surrogate standards (BDE51, BDE-115 and ${ }^{13}$ C-BDE-209) and copper sheets were added. The extract was concentrated and subject to purification/fractionation in a column (13 $\mathrm{mm}$ i.d.) consisting of silica gel and alumina, i.e., from bottom to top, with neutral alumina ( $6 \mathrm{~cm}, 3 \%$ deactivated), neutral silica gel $(2 \mathrm{~cm}, 3 \%$ deactivated), $25 \%$ sodium hydroxide silica $(5 \mathrm{~cm})$, neutral silica gel $(2 \mathrm{~cm}, 3 \%$ deactivated $), 44 \%$ sulfuric acid silica $(6 \mathrm{~cm})$ and anhydrous sodium sulfate (1 $\mathrm{cm})$. The fraction eluted with $80 \mathrm{~mL}$ of a hexane/dichloromethane mixture (1:1 in volume) was collected, concentrated and solvent exchanged with hexane. A known amount (2.5 ng) of internal standards (BDE-69, $\left.{ }^{13} \mathrm{C}-\mathrm{PCB}-208,{ }^{13} \mathrm{C}-\mathrm{BDE}-139\right)$ was added to each extract before GC/MS analysis.

Target HFRs (BDE-15, -17, -28, -47, -66, -71, -77, -85, -99, -100, -126, -138, -153, -154, $-166,-181,-183,-190,-196,-203,-204,-206,-207,-208$ and -209, DBDPE, DP and HBB) were quantified with a gas chromatograph coupled to a mass spectrometry (Shimadzu GC/MS-QP2010 Plus; Kyoto, Japan) in the negative chemical ionization mode and separated with a DB-5HT column $(15 \mathrm{~m} \times 0.25 \mathrm{~mm}$ i.d., $0.10 \mu \mathrm{m}$ film thickness $)$. Ultra-pure helium was used as the carrier gas at a flow rate of $1.5 \mathrm{~mL} \mathrm{~min}^{-1}$. Extract volume of $1 \mu \mathrm{L}$ was 
injected in the splitless/split mode at $290{ }^{\circ} \mathrm{C}$. Ion source and transfer line temperatures were set at 250 and $280{ }^{\circ} \mathrm{C}$, respectively. In addition, the oven temperature was initially held at $110{ }^{\circ} \mathrm{C}$ for $5 \mathrm{~min}$, ramped to $200{ }^{\circ} \mathrm{C}$ at $40{ }^{\circ} \mathrm{C} \mathrm{min}^{-1}$ (held for 4 min), increased to $260{ }^{\circ} \mathrm{C}$ at 10 ${ }^{\circ} \mathrm{C} \min ^{-1}$ (held for $1 \mathrm{~min}$ ) and finally programmed to $315{ }^{\circ} \mathrm{C}$ at $15{ }^{\circ} \mathrm{C} \mathrm{min}{ }^{-1}$ and held for 12 min. The qualification and qualifier ions of target analytes were described previously (Zhang et al., 2013).

\subsection{Quality assurance and quality control $(Q A / Q C)$}

A procedural blank, spiked blank, matrix blank, matrix spiked sample and three sample replicates were processed as quality control samples for every batch of 17 field samples. Matrix blank and matrix spiked samples were randomly selected from extracted soil samples. The recoveries (mean \pm standard deviation) for the target analytes in spiked samples were from $59 \pm 14 \%$ to $96 \pm 15 \%$. In addition, recoveries of the surrogate standards, i.e., BDE-51, BDE-115 and ${ }^{13}$ C-BDE-209 were $97 \pm 16 \%, 108 \pm 24 \%$ and $99 \pm 27 \%$, respectively, for all samples. With soil sample weights ranging from 14 to $29 \mathrm{~g}$ and the final extract volume of $50 \mu \mathrm{L}$, the reporting limits (RLs) were in the ranges from $0.002-0.18 \mathrm{ng} \mathrm{g}^{-1}$ for individual HFR congeners (Table 1).

\subsection{Data analysis}

All measured concentrations were blank corrected, but not surrogate standard recovery corrected, and were normalized to dry sample weight. Ordinary Kriging interpolation under ArcGIS Version 10.0 (ESRI, Redlands, USA) was used to map out the spatial distributions of soil HFR concentrations. Significant differences in concentrations and compositional profiles between/among different administrative districts and land-use types were examined with SPSS Version 13.0 (SPSS, Chicago, IL, USA) using one-way analysis of variance. Any 
significant difference between two sets of samples with unequal variances from the present study and previous studies was determined by a Welch's $t$-test. Criterion of significance was defined as $p<0.05$ in all statistical analyses.

\section{Results and discussion}

\subsection{HFRs levels and comparison with global values}

Concentrations of $\sum$ HFR (sum of BDE-15, -17, -28, -47, -66, -71, -77, -85, -99, -100, $126,-138,-153,-154,-166,-181,-183,-190,-196,-203,-204,-206,-207,-208$ and -209 , DBDPE, DP and HBB) varied in the range of $0.66-6500 \mathrm{ng} \mathrm{g}^{-1}$ with a mean (median) value of 290 (47) $\mathrm{ng} \mathrm{g}^{-1}$ (Table 1). Moreover, PBDEs were detectable with fairly high frequency, i.e., 64-100\% for individual PBDEs. BDE-209 was detectable in all samples with a concentration range of $0.20-4400$ and a mean value of $211 \mathrm{ng} \mathrm{g}^{-1}$ (Table 1). By comparison, the concentrations of other BDE congeners were in the range of $<\mathrm{RL}-500 \mathrm{ng} \mathrm{g}^{-1}$ with mean values of $0.06-11.9 \mathrm{ng} \mathrm{g}^{-1}$, significantly lower than those of BDE-209 $(p<0.05)$. The concentrations of BDE homologues increased from di-BDE to hexa-BDE, declined substantially from hexa-BDE to hepta-BDE and rose again from hepta-BDE to deca-BDE (Fig. 2a). Results from a comparison of soil PBDEs levels worldwide (Table S1) indicated that the concentrations of soil $\sum$ BDE (sum of 25 PBDEs except for BDE-209) and BDE-209 in the present study were in the midpoint of the global ranges.

As replacements of PBDEs, novel HFRs, i.e., DBDPE, DP and HBB were detected frequently (61\%-99\%; Table 1). The concentration range $\left(<\mathrm{RL}-530 \mathrm{ng} \mathrm{g}^{-1}\right)$ and mean $(29$ $\left.\mathrm{ng} \mathrm{g}^{-1}\right)$ of DBDPE were higher than those of DP $\left(<\mathrm{RL}-83\right.$ and $\left.3.2 \mathrm{ng} \mathrm{g}^{-1}\right)$ and HBB $(<\mathrm{RL}-$ 720 and $3.4 \mathrm{ng} \mathrm{g}^{-1}$ ) (Table 1). House dust from a rural region (an e-waste dismantling site) and an urban area (Guangzhou) also contained DBDPE as the predominant component of novel HFRs (Wang et al., 2010b). In addition, soil samples collected from Guiyu were also 
enriched with DBDPE accounting for more than $50 \%$ of the sum concentrations of HBB, DBDPE, 1,2-bis(2,4,6-tribromophenoxy) ethane, 2-ethylhexyl-2,3,4,5-tetrabromobenzoate, bis(2-ethylhexyl)-3,4,5,6-tetrabromophthalate, and pentabromoethylbenzene (Wang et al., 2016). A comparison of available soil DBDPE and DP data worldwide suggested that soil contamination by DBDPE and DP was generally more serious in China than in the selected countries (Table S1). Particularly, the concentrations of DBDPE and DP in the PRD and surrounding areas were greater than those in some major cities of China, e.g., Harbin (Ma et al., 2011), Huai' an (Wang et al., 2010a) and Taizhou (Xiao et al., 2013). Although HBB in soil has not been investigated previously, it has been detected in other environmental media, e.g., dust (Wang et al., 2010b), leaf surface particles (Tian et al., 2013) and sediment (Wu et al., 2010), terrestrial bird eggs (Sun et al., 2014), plants (Tian et al., 2013) and aquatic species (Wu et al., 2010) in the PRD and surrounding areas. Therefore, HBB as a novel HFR should also be monitored in the future.

\subsection{Spatial distribution patterns of HFRs}

Concentrations of $\sum$ HFR in the land-use types of residency, industry and landfill were higher than those in agriculture, forestry and drinking water source (Fig. S3a). However, there were no significant differences for concentrations of $\sum$ HFR among residency, industry and landfill or agriculture, forestry and drinking water source ( $p>0.05$; Table S2).

Moreover, the patterns of $\sum$ HFR in different land-use types were consistent with the distributions of $\sum$ BDE and BDE-209 (Fig. S3b and S3c), but a little different from that of the sum of DP, DBDPE and HBB with concentrations significantly lower in drinking water source than those in other land-use types (Fig. S3d). The current findings were also different from those of linear alkylbenzenes (LABs), polycyclic aromatic hydrocarbons (PAHs) and insecticides determined in the same samples. For example, the concentrations of LABs were 
higher in industry, agriculture and residency than in other land-use types (Wei et al., 2014a), whereas those of PAHs were not significantly different among the six land-use types (Wei et al., 2014b). In addition, legacy insecticides, i.e., organochlorine pesticides (OCPs) were mainly distributed in landfill, industry and residency while current-used insecticides, such as organophosphate and pyrethroid were concentrated in landfill, agriculture and residency (Wei et al., 2015). The disparity among different types of contaminants may be attributed to different sources and redistribution processes of these contaminants. LABs were largely from sewage discharge (Wei et al., 2014a) and PAHs were from combustion of coal and refined petroleum (Wei et al., 2014b). Insecticides were applied to agricultural areas for protecting crops against insects and urbanized areas for mosquito control (Wei et al., 2015).

Spatially, $\sum$ HFR concentrations were greater in the central PRD, i.e., Guangzhou, Foshan, Zhongshan, Dongguan and Shenzhen, than in the PRD's surrounding areas (Fig. 3). The spatial distribution patterns of $\sum$ BDE, BDE-209 and DBDPE were consistent with those of $\sum$ HFR (Figs. S4 and S5). Moreover, the mean contribution of BDE-209 to total PBDEs in the central PRD (81\%) was higher than those in the PRD's periphery (68\%), the East (59\%) and West regions $(65 \%)(p<0.05$; Fig. S6), while non-significant difference was observed on the relative abundance patterns of other brominated PBDEs (Fig. S6). These results suggested that the replacement rate of electronic products in the central PRD may be higher than those in the PRD's surrounding areas (Statistical Bureau of Guangdong Province, 2011). However, the contaminated sites with relatively higher DP levels were mainly located on Zhaoqing, Heyuan and Huizhou (Fig. S5a). This difference may be due to the fact that DP has been used as an alternative HFR in recent years and many manufacturing plants in the central PRD have been relocated to the western and eastern parts of the PRD with lower levels of urbanization and industrialization (Yang and Mao, 2014). 
The spatial patterns of $\sum$ HFR, as well as $\sum$ BDE, BDE-209 and sum of DP, DBDPE and HBB appeared to be consistent with those of population density, gross domestic production (GDP) and level of urbanization, i.e., high $\sum$ HFR concentrations were congested in the central PRD with high population density, GDP and urbanization levels (Figs. 4a and S7). Moreover, the linear correlations between $\sum$ HFR concentrations and GDP $\left(r^{2}=0.44, p<\right.$ 0.01; Fig. 4b), population density $\left(r^{2}=0.32, p<0.05\right.$; Fig. $\left.4 c\right)$ and urbanization levels $\left(r^{2}=\right.$ $0.57, p<0.01$; Fig. $4 d$ ) were similar and moderately significant. Similarly, concentrations of ¿BDE, BDE-209 and sum of DP, DBDPE and HBB were moderately correlated with social and economic factors (GDP, population density and urbanization levels; $r^{2}=0.32-0.61, p<$ 0.05; Fig. S8), except the relations between GDP and concentrations of $\sum \operatorname{BDE}\left(r^{2}=0.13, p>\right.$ 0.05; Fig. S8a), and GDP and concentrations of sum of DP, DBDPE and HBB $\left(r^{2}=0.26, p>\right.$ 0.05; Fig. S8c). In general, the results indicated that social and economic factors appear to have dominated the spatial distributions of $\sum$ HFR concentrations in the PRD, which was also found in our previous study conducted in the coastal zone off southern China (Liu et al., 2014). On the other hand, there was only a weak correlation $\left(r^{2}=0.13, p<0.001\right.$; Fig. S9) between log-transformed $\sum$ HFR concentrations and log-transformed TOC contents. The same results were also observed between log-transformed individual HFR concentrations and log-transformed TOC contents with the $r^{2}$ values ranging from 0.01 to 0.24 , indicating that TOC was not a governing factor for the spatial distribution of soil HFRs. It is interesting to note that $\sum$ HFR concentrations in the drinking water source were significantly correlated with log-transformed TOC contents $\left(r^{2}=0.50, p<0.001\right)$, but not for other land-use types $\left(r^{2}\right.$ $=0.07-0.34)$. This was probably because the sampling areas in the drinking water source are away from urban centers and have low population density, so that HFRs in these areas may have been transported from other areas through the atmosphere. It was further corroborated by the lower fraction of BDE-209 in the drinking water source $(68 \%)$ than in other land-use 
types (71-83\%; Fig. S6), as heavily brominated PBDEs were less likely to migrate through the atmosphere than lightly brominated PBDEs (Ruiz-Fernández et al., 2014).

\subsection{Compositions of HFRs}

BDE-209 was the predominant BDE congener, accounting for $72 \pm 18 \%$ of the total BDE concentrations (Fig. S10), consistent with the results of previous studies on agricultural soils (Zou et al., 2007) and e-waste disposal soils in Guiyu of southern China (Leung et al., 2007). In addition, the relative abundances of BDE-206 and -207 were $1.4 \%$ and $4.3 \%$, respectively, likely due to the degradation of BDE-209 in the environment (Gerecke et al., 2005). The main low brominated BDE congeners were BDE-47 and -99, which contributed $2.3 \%$ and $3.1 \%$ of the total BDE concentrations. La Guardia et al. (2006) revealed that BDE47 and -99 were the major components of industrial products of Penta-BDE. However, the correlation between BDE-47 and -99 in the present study was weak $\left(r^{2}=0.24, p<0.001\right.$; Fig. S11a). Because BDE-47 and -99 in soils may undergo various physicochemical processes, their relative abundances may change (Xu et al., 2015). Moreover, Xu et al. (2015) found that the ratio of BDE-47 to (BDE-99 + BDE-100) deviated more from commercial PentaBDE products in outdoor particles than in indoor samples. Aside from BDE-209, the abundance of BDE-153 was high (mean: 5\%; Fig. S10), which is attributed to the abundant occurrence of BDE-153 in the technical products of Penta-BDE and Octa-BDE (La Guardia et al., 2006). In 2006, commercial products of Penta-BDE and Octa-BDE were officially banned by the Chinese government, but they were still used privately (Zhang et al., 2009).

Principal component analysis was used to analyze the sources of PBDEs, which obtained six components contributing to $85 \%$ of the total variance in the PBDE data (Table S3). The first component, accounting for $30 \%$ of the total variance, predominantly contained BDE-209, $-208,-207,-206,-204,-196,-181$ and -15 , and is related to the usage of industrial 
products of Deca-BDE (La Guardia et al., 2006). The second component, responsible for $13 \%$ of the total variance, was enriched with BDE-47, -99 and -100 from the usage of industrial products of Penta-BDE in outdoor particles. Overall, the results of principal component analysis and relative abundances of individual PBDEs indicated that PBDEs in soil of the PRD and surrounding areas may have been derived from the use of Penta- and Deca-BDE, as well as degradation of BDE-209.

Furthermore, the contributions of DBDPE or HBB were not significantly different in different districts $(p>0.05$; Fig. S12), probably suggesting that the emission sources and fate of DBDPE or HBB were similar among different districts. Possible input sources include, but are not limited to, textiles, electronics, furniture and thermoplastics as investigated previously (La Guardia et al., 2013). The widespread use of the household appliances is obviously a result of economic prosperity in recent years. For example, the numbers of color television sets, washing machines, refrigerators and mobile phones were 119, 45.8, 49.1 and 82.4 per 100 rural families in 2010 , as compared to $143,97.7,96.6$ and 91.8 per 100 urban families in 2010 (China Statistical Yearbook, 2011). The ratios of anti-DP $\left(f_{\text {anti-DP }} ; f_{\text {anti-DP }}=\right.$ anti-DP / (anti-DP + syn-DP)) were in the range of 0.18-1.00 (mean \pm standard deviation: $0.73 \pm 0.15$ ), close to those in commercial products of DP (mean: 0.65-0.80) (Hoh et al., 2006; Tomy et al., 2007). i.e., DP in soils may have been resulted from DP-containing industrial products. The spatial distribution pattern of $f_{\text {anti-DP }}$ (Fig. S13) was consistent with that of DP concentrations (Fig. S5a). This finding was similar to those from the previous studies (Qi et al., 2010; Sverko et al., 2007; Wang et al., 2010a). In addition, log-transformed concentrations of BDE-209 and DBDPE were significantly correlated $\left(r^{2}=0.70, p<0.001\right.$; Fig. S11c), indicating that the behavior and fate of these two flame retardant compounds were similar and thereby DBDPE was the main substitute of Deca-BDE (La Guardia et al., 2012). However, the fraction of DBDPE (DBDPE/(DBDPE+BDE-209)) was greater than 0.5 in 
$9.2 \%$ of the samples only, which may indicate low replacement of BDE-209 by DBDPE in the PRD and surrounding areas. A recent study also found the fraction of DBDPE was lower than 0.5 in most soil samples collected in northern China (Lin et al., 2015).

\subsection{Impacts of HFRs from e-waste disposal activities on surrounding areas}

Shijiao and Longtang in Qingyuan are two of the largest e-waste dismantling areas around the world, with approximately 1.7 million tons of e-waste recycled annually (Luo et al., 2009a). In the present study, the mean $\sum$ HFR concentration in Qingyuan was $160 \mathrm{ng} \mathrm{g}^{-1}$, and the sample containing the highest $\sum$ HFR concentration $\left(700 \mathrm{ng} \mathrm{g}^{-1}\right)$ was collected at a location between several yards where e-waste recycling activities were actually conducted in Shijiao. The sum of PBDE concentrations in this sample was $630 \mathrm{ng} \mathrm{g}^{-1}$, lower than those in abandoned dump soil of e-waste (25000 $\mathrm{ng} \mathrm{g}^{-1}$ ) (Yang et al., 2008) and soil in e-waste dismantling area in Longtang (2900 $\left.\mathrm{ng} \mathrm{g}^{-1}\right)(\mathrm{Li}$ et al., 2011) $(p<0.05)$, but higher than that in soil near an e-waste recycling region (mean: $275 \mathrm{ng} \mathrm{g}^{-1} ; p<0.05$ ) (Luo et al., 2009a).

In an attempt to examine the transport of PBDEs discharged from e-waste recycling activities, the mean concentration $\left(28.1 \mathrm{ng} \mathrm{g}^{-1}\right)$ of PBDEs in the land type of drinking water sources was taken as a reference level. The highest concentration $\left(630 \mathrm{ng} \mathrm{g}^{-1}\right)$ of total PBDEs in the soil sample mentioned above was 4.1-9.9 times those in three soil samples collected near the e-waste recycling region, which is less than $3 \mathrm{~km}$ from the waste recycling yards. Apparently soil HFR concentrations gradually decreased with increasing distance from ewaste recycling sites. Furthermore, the concentrations of PBDEs declined to $18.3 \mathrm{ng} \mathrm{g}^{-1}$, which were comparable to those in drinking water sources, at a distance less than $10 \mathrm{~km}$ from the e-waste recycling yards.

Luo et al. (2009b) found that the mean PBDE concentration in a sample collected at approximately $10 \mathrm{~m}$ from an e-waste recycling yard was $2689 \mathrm{ng} \mathrm{g}^{-1}, 64$ times of mean 
concentration $\left(42.2 \mathrm{ng} \mathrm{g}^{-1}\right)$ of those in farmland soil samples collected at approximately $2 \mathrm{~km}$ downwind from the e-waste recycling yard. Li et al. (2011) also showed that the concentrations of total PBDEs and polychlorinated biphenyls in soil close to Longtang ewaste recycling yards were 2908 and $1891 \mathrm{ng} \mathrm{g}^{-1}$, respectively, and decreased to 4.66 and 449 $\mathrm{ng} \mathrm{g}^{-1}$ at $2.5 \mathrm{~km}$ away from the e-waste recycling yards. Moreover, DP concentrations decreased by a factor of 5000 within $20 \mathrm{~km}$ from the e-waste recycling region of Qingyuan (Yu et al., 2010). Zhao et al. (2009) suggested that the transport patterns of lightly and heavily brominated PBDEs were similar at a short-range scale. All these findings support the notion that HFRs released from e-waste recycling activities may largely remain in surrounding areas.

\section{Conclusions}

The present study indicated that the soil of the central PRD contained the greatest concentrations of HFRs, whereas soil of the PRD's surrounding areas included the least abundant HFRs. BDE-209 was the predominant compound, obviously derived from the huge amounts of technical Deca-BDE products used in the study regions. Moderate correlations were found between HFR concentrations and certain socioeconomic factors, such as population density, GDP and level of urbanization, indicating that anthropogenic sources moderately impacted the spatial patterns of soil HFR concentrations. Additionally, concentrations of HFRs discharged from e-waste recycling areas tended to sharply decrease with increasing distance from the sites of discharge, indicating a confined impact of e-waste recycling and disposal on the surrounding environments. Overall, health risk of HFRs in metropolis with intense human activities should be further concerned in future studies.

\section{Acknowledgments}


This work was financially supported by the National Science Foundation of China (Nos. 41390240 and 41329002) and Guangzhou Institute of Geochemistry, Chinese Academy of Sciences (No. SKLOG2015A01). This is contribution No. IS-XXXX from GIGCAS.

\section{Appendix. Supplementary data}

Supplementary material associated with this article can be found, in the online version, at

\section{References}

Alaee, M., Arias, P., Sjödin, A., Bergman, Å., 2003. An overview of commercially used brominated flame retardants, their applications, their use patterns in different countries/regions and possible modes of release. Environ. Int. 29, 683-689.

Chen, J., 2007. Rapid urbanization in China: a real challenge to soil protection and food security. CATENA 69, 1-15.

China Statistical Yearbook, 2011. http://www.stats.gov.cn/tjsj/ndsj/2011/indexch.htm (accessed on February 20, 2016).

Covaci, A., Harrad, S., Abdallah, M.A.E., Ali, N., Law, R.J., Herzke, D., de Wit, C.A., 2011. Novel brominated flame retardants: a review of their analysis, environmental fate and behaviour. Environ. Int. 37, 532-556.

Csiszar, S.A., Diamond, M.L., Daggupaty, S.M., 2014. The magnitude and spatial range of current-use urban PCB and PBDE emissions estimated using a coupled multimedia and air transport model. Environ. Sci. Technol. 48, 1075-1083.

Ding, N., Wang, T., Chen S.-J., Yu, M., Zhu, Z.-C., Tian, M., Luo, X.-J., Mai, B.-X., 2016. Brominated flame retardants (BFRs) in indoor and outdoor air in a community in Guangzhou, a megacity of southern China. Environ. Pollut. 212, 457-463.

Du, J., Sun, P., Feng, Z., Zhang, X., Zhao, Y., 2016. The biosorption capacity of biochar for 4-bromodiphengl ether: study of its kinetics, mechanism, and use as a carrier for immobilized bacteria. Environ. Sci. Pollut. Res. 23, 3770-3780.

Engelke, P., 2012. The security of cities: development, environmental, and conflict on an urbanizing planet. The Henry L. Stimson Center All rights reserved. No part of this publication may be reproduced or transmitted in any form or by any means without prior written consent from the Stimson Center, Washington, DC 20036. 
Gerecke, A.C., Hartmann, P.C., Heeb, N.V., Kohler, H.-P.E., Giger, W., Schmid, P., Zennegg, M., Kohler, M., 2005. Anaerobic degradation of decabromodiphenyl ether. Environ. Sci. Technol. 39, 1078-1083.

Hoh, E., Zhu, L., Hites, R.A., 2006. Dechlorane plus, a chlorinated flame retardant, in the Great Lakes. Environ. Sci. Technol. 40, 1184-1189.

La Guardia, M.J., Hale, R.C., Harvey, E., 2006. Detailed polybrominated diphenyl ether (PBDE) congener composition of the widely used penta-, octa-, and deca-PBDE technical flame-retardant mixtures. Environ. Sci. Technol. 40, 6247-6254.

La Guardia, M.J., Hale, R.C., Harvey, E., Mainor, T.M., Ciparis, S., 2012. In situ accumulation of HBCD, PBDEs, and several alternative flame-retardants in the bivalve (Corbicula fluminea) and gastropod (Elimia proxima). Environ. Sci. Technol. 46, 5798-5805.

La Guardia, M.J., Hale, R.C., Newman, B., 2013. Brominated flame-retardants in SubSaharan Africa: burdens in inland and coastal sediments in the eThekwini metropolitan municipality, South Africa. Environ. Sci. Technol. 47, 9643-9650.

Law, R. J., Bersuder, P., Barry, J., Wilford, B. H., Allchin, C. R., Jepson, P. D., 2008. A significant downturn in levels of hexabromocyclododecane in the blubber of harbor porpoises (Phocoena phocoena) stranded or bycaught in the UK: an update to 2006. Environ. Sci. Technol. 42, 9104-9109.

Leung, A.O., Luksemburg, W.J., Wong, A.S., Wong, M.H., 2007. Spatial distribution of polybrominated diphenyl ethers and polychlorinated dibenzo-p-dioxins and dibenzofurans in soil and combusted residue at Guiyu, an electronic waste recycling site in Southeast China. Environ. Sci. Technol. 41, 2730-2737.

Li, H., Bai, J., Li, Y., Cheng, H., Zeng, E.Y., You, J., 2011. Short-range transport of contaminants released from e-waste recycling site in South China. J. Environ. Monit. 13, 836-843.

Li, X., Luo, X., Mai, B., Liu, J., Chen, L., Lin, S., 2014. Occurrence of quaternary ammonium compounds (QACs) and their application as a tracer for sewage derived pollution in urban estuarine sediments. Environ. Pollut. 185, 127-133.

Lin, T., Gibson, V., Cui, S., Yu, C.-P., Chen, S., Ye, Z., Zhu, Y.-G., 2014. Managing urban nutrient biogeochemistry for sustainable urbanization. Environ. Pollut. 192, 244-250.

Lin, Y., Ma, J., Qiu, X., Zhao, Y., Zhu, T., 2015. Levels, spatial distribution, and exposure risks of decabromodiphenylethane in soils of North China. Environ. Sci. Pollut. Res. 22, 13319-13327.

Liu, H.-H., Hu, Y.-J., Luo, P., Bao, L.-J., Qiu, J.-W., Leung, K.M.Y., Zeng, E.Y., 2014. Occurrence of halogenated flame retardants in sediment off an urbanized coastal zone: association with urbanization and industrialization. Environ. Sci. Technol. 48, 8465-8473.

Luo, P., Bao, L.-J., Wu, F.-C., Li, S.-M., Zeng, E.Y., 2014. Health risk characterization for resident inhalation exposure to particle-bound halogenated flame retardants in a typical ewaste recycling zone. Environ. Sci. Technol. 48, 8815-8822. 
Luo, X.-J., Liu, J., Luo, Y., Zhang, X.-L., Wu, J.-P., Lin, Z., Chen, S.-J., Mai, B.-X., Yang, Z.-Y., 2009a. Polybrominated diphenyl ethers (PBDEs) in free-range domestic fowl from an e-waste recycling site in South China: levels, profile and human dietary exposure. Environ. Int. 35, 253-258.

Luo, Y., Luo, X.-J., Lin, Z., Chen, S.-J., Liu, J., Mai, B.-X., Yang, Z.-Y., 2009b.

Polybrominated diphenyl ethers in road and farmland soils from an e-waste recycling region in Southern China: concentrations, source profiles, and potential dispersion and deposition. Sci. Total Environ. 407, 1105-1113.

Ma, W.-L., Liu, L.-Y., Qi, H., Sun, D.-Z., Shen, J.-M., Wang, D.-G., Li, Y.-F., 2011. Dechlorane plus in multimedia in northeastern Chinese urban region. Environ. Int. 37, 66-70.

Martin, M., Lam, P.K.S., Richardson, B.J., 2004. An Asian quandary: where have all of the PBDEs gone? Mar. Pollut. Bull. 49, 375-382.

Peng, Y., Wu, J.-P., Tao, L., Mo, L., Tang, B., Zhang, Q., Luo, X.-J., Zou, F.-S., Mai, B.-X., 2015. Contaminants of legacy and emerging concern in terrestrial passerines from a nature reserve in South China: residue levels and inter-species differences in the accumulation. Environ. Pollut. 203, 7-14.

Qi, H., Liu, L., Jia, H., Li, Y.-F., Ren, N.-Q., You, H., Shi, X., Fan, L., Ding, Y., 2010. Dechlorane plus in surficial water and sediment in a northeastern Chinese river. Environ. Sci. Technol. 44, 2305-2308.

Ruiz-Fernández, A.C., Ontiveros-Cuadras, J.F., Sericano, J.L., Sanchez-Cabeza, J.-A., Liong Wee Kwong, L., Dunbar, R.B., Mucciarone, D.A., Pérez-Bernal, L.H., Páez-Osuna, F., 2014. Long-range atmospheric transport of persistent organic pollutants to remote lacustrine environments. Sci. Total Environ. 493, 505-520.

Shi, T., Chen, S.-J., Luo, X.-J., Zhang, X.-L., Tang, C.-M., Luo, Y., Ma, Y.-J., Wu, J.-P., Peng, X.-Z., Mai, B.-X., 2009. Occurrence of brominated flame retardants other than polybrominated diphenyl ethers in environmental and biota samples from southern China. Chemosphere 74, 910-916.

Statistical Bureau of Guangdong Province, 2011. Guangdong Statistical Yearbook 2011. http://www.gdstats.gov.cn/tjnj/2011/table/21/e21-02-0.htm (accessed on February 20, 2016).

Sun, Y.-X., Xu, X.-R., Hao, Q., Luo, X.-J., Ruan, W., Zhang, Z.-W., Zhang, Q., Zou, F.-S., Mai, B.-X., 2014. Species-specific accumulation of halogenated flame retardants in eggs of terrestrial birds from an ecological station in the Pearl River Delta, South China.

Chemosphere 95, 442-447.

Sverko, E., Tomy, G.T., Marvin, C.H., Zaruk, D., Reiner, E., Helm, P.A., Hill, B., McCarry, B.E., 2007. Dechlorane plus levels in sediment of the lower Great Lakes. Environ. Sci. Technol. 42, 361-366.

Sverko, E., Tomy, G.T., Reiner, E.J., Li, Y.-F., McCarry, B.E., Arnot, J.A., Law, R.J., Hites, R.A., 2011. Dechlorane plus and related compounds in the environment: a review. Environ. Sci. Technol. 45, 5088-5098. 
Szolnoki, Z., Farsang, A., Puskás, I., 2013. Cumulative impacts of human activities on urban garden soils: origin and accumulation of metals. Environ. Pollut. 177, 106-115.

Tian, M., Chen, S.J., Luo, Y., Wang, J., Zhu, Z.C., Luo, X.J., Mai, B.X., 2013. Air-plant exchange of brominated flame retardants at a rural site: influencing factor, interspecies difference, and forest scavenging. Environ. Toxicol. Chem. 32, 1248-1253.

Tittlemier, S.A., Halldorson, T., Stern, G.A., Tomy, G.T., 2002. Vapor pressures, aqueous solubilities, and Henry's law constants of some brominated flame retardants. Environ. Toxicol. Chem. 21, 1804-1810.

Tomy, G.T., Pleskach, K., Ismail, N., Whittle, D.M., Helm, P.A., Sverko, E., Zaruk, D., Marvin, C.H., 2007. Isomers of dechlorane plus in Lake Winnipeg and Lake Ontario food webs. Environ. Sci. Technol. 41, 2249-2254.

Wang, D.-G., Yang, M., Qi, H., Sverko, E., Ma, W.-L., Li, Y.-F., Alaee, M., Reiner, E.J., Shen, L., 2010a. An Asia-specific source of dechlorane plus: concentration, isomer profiles, and other related compounds. Environ. Sci. Technol. 44, 6608-6613.

Wang, J., Ma, Y.-J., Chen, S.-J., Tian, M., Luo, X.-J., Mai, B.-X., 2010b. Brominated flame retardants in house dust from e-waste recycling and urban areas in South China: implications on human exposure. Environ. Int. 36, 535-541.

Wang, S., Wang, Y., Song, M., Luo, C., Li, J., Zhang, G., 2016. Distributions and compositions of old and emerging flame retardants in the rhizosphere and non-rhizosphere soil in an e-waste contaminated area of South China. Environ. Pollut. 208, Part B, 619-625.

Ward, J., Mohapatra, S. P., Mitchell, A., 2008. An overview of policies for managing polybrominated diphenyl ethers (PBDEs) in the Great Lakes basin. Environ. Int. 34, 11481156.

Wei, G.-L., Bao, L.-J., Guo, L.-C., He, Z.-C., Zeng, E.Y., 2014a. Utility of soil linear alkylbenzenes to assess regional anthropogenic influences in a rapidly urbanizing watershed. Sci. Total Environ. 487, 528-536.

Wei, Y.-L., Bao, L.-J., Wu, C.-C., He, Z.-C., Zeng, E.Y., 2014b. Association of soil polycyclic aromatic hydrocarbon levels and anthropogenic impacts in a rapidly urbanizing region: spatial distribution, soil-air exchange and ecological risk. Sci. Total Environ. 473474, 676-684.

Wei, Y.-L., Bao, L.-J., Wu, C.-C., He, Z.-C., Zeng, E.Y., 2015. Assessing the effects of urbanization on the environment with soil legacy and current-use insecticides: a case study in the Pearl River Delta, China. Sci. Total Environ. 514, 409-417.

Wu, J.-P., Guan, Y.-T., Zhang, Y., Luo, X.-J., Zhi, H., Chen, S.-J., Mai, B.-X., 2010. Trophodynamics of hexabromocyclododecanes and several other non-PBDE brominated flame retardants in a freshwater food web. Environ. Sci. Technol. 44, 5490-5495.

Xiao, K., Wang, P., Zhang, H., Shang, H., Li, Y., Li, X., Ren, D., Chen, W., Zhang, Q., 2013. Levels and profiles of dechlorane plus in a major e-waste dismantling area in China. Environ. Geochem. Heal. 35, 625-631. 
Xu, F., Liu, Y., Wang, J., Zhang, G., Zhang, W., Liu, L., Wang, J., Pan, B., Lin, K., 2015. Characterization of heavy metals and brominated flame retardants in the indoor and outdoor dust of e-waste workshops: implication for on-site human exposure. Environ. Sci. Pollut. Res. $22,5469-5480$.

Yang, B., Mao, Y., 2014. Industrial relocation policy and firm migration: an empirical analysis from Guangdong industrial relocation survey data. South China Journal of Economics 3, 1-21.

Yang, Z., Zhao, X., Zhao, Q., Qin, Z., Qin, X., Xu, X., Jin, Z., Xu, C., 2008. Polybrominated diphenyl ethers in leaves and soil from typical electronic waste polluted area in South China. Bull. Environ. Contam. Toxicol. 80, 340-344.

Yu, L.-H., Luo, X.-J., Liu, H.-Y., Zeng, Y.-H., Zheng, X.-B., Wu, J.-P., Yu, Y.-J., Mai, B.X., 2014. Organohalogen contamination in passerine birds from three metropolises in China: geographical variation and its implication for anthropogenic effects on urban environments. Environ. Pollut. 188, 118-123.

Yu, Z., Lu, S., Gao, S., Wang, J., Li, H., Zeng, X., Sheng, G., Fu, J., 2010. Levels and isomer profiles of dechlorane plus in the surface soils from e-waste recycling areas and industrial areas in South China. Environ. Pollut. 158, 2920-2925.

Zhang, B., Li, H., Wei, Y., You, J., 2013. Bioaccumulation kinetics of polybrominated diphenyl ethers and decabromodiphenyl ethane from field-collected sediment in the oligochaete, Lumbriculus Variegatus. Environ. Toxicol. Chem. 32, 2711-2718.

Zhang, X.-L., Luo, X.-J., Chen, S.-J., Wu, J.-P., Mai, B.-X., 2009. Spatial distribution and vertical profile of polybrominated diphenyl ethers, tetrabromobisphenol $\mathrm{A}$, and decabromodiphenylethane in river sediment from an industrialized region of South China. Environ. Pollut. 157, 1917-1923.

Zhao, Y.-X., Qin, X.-F., Li, Y., Liu, P.-Y., Tian, M., Yan, S.-S., Qin, Z.-F., Xu, X.-B., Yang, Y.-J., 2009. Diffusion of polybrominated diphenyl ether (PBDE) from an e-waste recycling area to the surrounding regions in Southeast China. Chemosphere 76, 1470-1476.

Zou, M.-Y., Ran, Y., Gong, J., Mai, B.-X., Zeng, E.Y., 2007. Polybrominated diphenyl ethers in watershed soils of the Pearl River Delta, China: occurrence, inventory, and fate. Environ. Sci. Technol. 41, 8262-8267. 
Table 1. Concentrations (range, median, mean \pm standard (SD); $\mathrm{ng} \mathrm{g}^{-1}$ dry weight), detection frequencies (DF; \%) and reporting limits (RLs; $\mathrm{ng} \mathrm{g}^{-1}$ dry weight) of individual and total halogenated flame retardants (HFRs) in soil in the Pearl River Delta and surrounding areas, southern China.

\begin{tabular}{|c|c|c|c|c|c|}
\hline Target & range & median & mean $\pm \mathrm{SD}$ & $\mathrm{DF}$ & RLs \\
\hline BDE-15 & $<\mathrm{RL}-2.5$ & 0.01 & $0.06 \pm 0.26$ & 65 & $0.002-0.004$ \\
\hline BDE-17 & $<\mathrm{RL}-22$ & 0.02 & $0.19 \pm 1.46$ & 78 & $0.002-0.004$ \\
\hline BDE-28 & $<\mathrm{RL}-3.7$ & 0.02 & $0.14 \pm 0.44$ & 74 & $0.002-0.004$ \\
\hline BDE-47 & $<\mathrm{RL}-30$ & 0.39 & $1.05 \pm 2.9$ & 98 & $0.002-0.004$ \\
\hline BDE-66 & $<\mathrm{RL}-17.4$ & 0.12 & $0.46 \pm 1.34$ & 78 & $0.002-0.004$ \\
\hline BDE-71 & $<\mathrm{RL}-500$ & 0.10 & $2.7 \pm 33$ & 84 & $0.002-0.004$ \\
\hline BDE-77 & $<\mathrm{RL}-3.8$ & 0.16 & $0.36 \pm 0.60$ & 90 & $0.002-0.004$ \\
\hline BDE-85 & $<\mathrm{RL}-16.6$ & 0.13 & $0.59 \pm 1.78$ & 89 & $0.002-0.004$ \\
\hline BDE-99 & $<\mathrm{RL}-76$ & 0.54 & $2.8 \pm 8.8$ & 94 & $0.003-0.005$ \\
\hline BDE-100 & $<\mathrm{RL}-44$ & 0.30 & $1.01 \pm 3.9$ & 92 & $0.002-0.004$ \\
\hline BDE-126 & $<\mathrm{RL}-13.2$ & 0.22 & $0.64 \pm 1.47$ & 88 & $0.002-0.004$ \\
\hline BDE-138 & $<\mathrm{RL}-27$ & 0.14 & $0.90 \pm 3.1$ & 82 & $0.002-0.004$ \\
\hline BDE-153 & $<\mathrm{RL}-111$ & 0.82 & $5.2 \pm 13.6$ & 93 & $0.002-0.004$ \\
\hline BDE-154 & $<\mathrm{RL}-28$ & 0.11 & $0.77 \pm 3.0$ & 78 & $0.002-0.004$ \\
\hline BDE-166 & $<\mathrm{RL}-27$ & 0.10 & $0.89 \pm 3.1$ & 83 & $0.002-0.004$ \\
\hline BDE-181 & $<\mathrm{RL}-129$ & 0.09 & $2.2 \pm 11.0$ & 77 & $0.003-0.007$ \\
\hline BDE-183 & $<\mathrm{RL}-320$ & 0.15 & $1.75 \pm 21$ & 86 & $0.003-0.007$ \\
\hline BDE-190 & $<\mathrm{RL}-37$ & 0.02 & $0.53 \pm 3.4$ & 64 & $0.003-0.007$ \\
\hline BDE-196 & $<\mathrm{RL}-83$ & 0.10 & $1.19 \pm 6.6$ & 82 & $0.007-0.014$ \\
\hline BDE-203 & $<\mathrm{RL}-92$ & 0.25 & $1.51 \pm 7.2$ & 76 & $0.007-0.014$ \\
\hline BDE-204 & $<\mathrm{RL}-47$ & 0.09 & $0.77 \pm 3.7$ & 80 & $0.007-0.014$ \\
\hline BDE-206 & $<\mathrm{RL}-142$ & 0.40 & $3.9 \pm 13.4$ & 96 & $0.009-0.018$ \\
\hline BDE-207 & $<\mathrm{RL}-480$ & 1.25 & $11.9 \pm 43$ & 95 & $0.009-0.018$ \\
\hline BDE-208 & $<\mathrm{RL}-85$ & 0.18 & $2.0 \pm 7.4$ & 96 & $0.009-0.018$ \\
\hline BDE-209 & $0.20-4400$ & 26 & $211 \pm 620$ & 100 & $0.017-0.036$ \\
\hline HBB & $<\mathrm{RL}-720$ & 0.02 & $3.4 \pm 48$ & 61 & $0.017-0.036$ \\
\hline syn-DP & $<\mathrm{RL}-28$ & 0.17 & $0.89 \pm 2.8$ & 75 & $0.034-0.072$ \\
\hline anti-DP & $<\mathrm{RL}-66$ & 0.43 & $2.3 \pm 6.3$ & 90 & $0.034-0.072$ \\
\hline DBDPE & $<\mathrm{RL}-530$ & 8.2 & $29 \pm 66$ & 99 & $0.086-0.18$ \\
\hline$\sum \mathrm{BDE}^{\mathrm{a}, \mathrm{e}}$ & $0.17-1320$ & 8.7 & $43 \pm 133$ & 100 & $0.09-0.18$ \\
\hline$\sum \mathrm{BDE}^{\mathrm{b}, \mathrm{e}}$ & $0.37-5700$ & 34.5 & $250 \pm 740$ & 100 & $0.10-0.22$ \\
\hline $\mathrm{DP}^{\mathrm{c}, \mathrm{e}}$ & $<\mathrm{RL}-83$ & 0.61 & $3.2 \pm 8.6$ & 90 & $0.07-0.14$ \\
\hline$\sum \mathrm{HFR}^{\mathrm{d}, \mathrm{e}}$ & $0.66-6500$ & 47 & $290 \pm 820$ & 100 & $0.27-0.56$ \\
\hline
\end{tabular}

${ }^{\mathrm{a}}$ Sum of BDE-15, -17, -28, -47, -66, -71, -77, -85, -99, -100, -126, -138, -153, -154, -166, $181,-183,-190,-196,-203,-204,-206,-207$, and -208 .

${ }^{\mathrm{b}}$ Sum of BDE-15, -17, -28, -47, -66, -71, -77, -85, -99, -100, -126, -138, -153, -154, -166, $181,-183,-190,-196,-203,-204,-206,-207,-208$, and -209.

${ }^{\mathrm{c}}$ Sum of syn- and anti-DP.

${ }^{\mathrm{d}}$ Sum of BDE-15, -17, -28, -47, -66, -71, -77, -85, -99, -100, -126, -138, -153, -154, -166, $181,-183,-190,-196,-203,-204,-206,-207,-208$ and -209, DBDPE, syn- and anti-DP, and HBB.

${ }^{\mathrm{e}}$ At least one analyte was detected with higher concentration than the RL in sample. 


\section{Figure captions}

Fig. 1. Map of the sampling sites in the Pearl River Delta (PRD) and surrounding areas, including (a) four geographic regions marked with different colors: (I) West region (YJ and YF; in white); (П) the PRD’s periphery (ZQ, QY, JM, and HZ; in light grey); (Ш) the central PRD (GZ, FS, DG, ZS, ZH, and SZ; in dark grey); and (IV) East region (HY, SW, and SG; in white) and (b) six land-use types, i.e., industry, agriculture, landfill, residency, forestry, and drinking water source. YJ, YF, ZQ, QY, JM, HZ, GZ, FS, DG, ZS, ZH, SZ, HY, SW, and SG are acronyms of district names, i.e., Yangjiang, Yunfu, Zhaoqing, Qingyuan, Jiangmen, Huizhou, Guangzhou, Foshan, Dongguan, Zhongshan, Zhuhai, Shenzhen, Heyuan, Shanwei, and Shaoguan, respectively.

Fig. 2. Sum concentrations of (a) BDE homologs and (b) classes of halogenated flame retardants. $\mathrm{Di}-\mathrm{BDE}=\mathrm{BDE}-15$; tri-BDE $=\mathrm{BDE}-17$ and -28 ; tetra-BDE $=\mathrm{BDE}-$ 47, $-66,-71$ and -77 ; penta-BDE $=$ BDE-85, $-99,-100$ and -126 ; hexa-BDE $=$ BDE-138, -153, -154 and -166; hepta-BDE = BDE-181, -183 and -190; octa$\mathrm{BDE}=\mathrm{BDE}-196,-203$ and -204 ; nona-BDE = BDE-206, -207 and -208 ; and deca-BDE $=$ BDE-209. BDEs $=$ BDE-15, -17, -28, -47, -66, -71, -77, -85, -99, $100,-126,-138,-153,-154,-166,-181,-183,-190,-196,-203,-204,-206,-207$ and -208. Error bars adjacent to the bottom and upper parts of each box stand for the 10th and 90th percentiles, respectively, and horizontal lines from the bottom to the top of each box stand for the 25 th, 50 th and 75 th percentiles. The dotted lines represent mean concentrations.

Fig. 3. Spatial distribution patterns of soil halogenated flame retardants (ng $\mathrm{g}^{-1}$ dry weight) in the study region (Fig. 1), which is the sum of BDE-15, -17, -28, -47, $66,-71,-77,-85,-99,-100,-126,-138,-153,-154,-166,-181,-183,-190,-196$, 
$-203,-204,-206,-207,-208$ and -209 , hexabromobenzene, bis(hexachlorocyclopentadieno)cyclooctane and decabromodiphenyl ethane. YJ, YF, ZQ, QY, JM, HZ, GZ, FS, DG, ZS, ZH, SZ, HY, SW and SG are acronyms of district names, i.e., Yangjiang, Yunfu, Zhaoqing, Qingyuan, Jiangmen, Huizhou, Guangzhou, Foshan, Dongguan, Zhongshan, Zhuhai, Shenzhen, Heyuan, Shanwei and Shaoguan, respectively.

Fig. 4. (a) Population density (in hundred person $\mathrm{km}^{-2}$ ), gross domestic production (GDP; in ten billion RMB), urbanization levels (\%) and concentrations of halogenated flame retardants (HFRs; in ten $\mathrm{ng} \mathrm{g}^{-1}$ dry weight), as well as correlations between the concentrations of HFRs and (b) population densities, (c) GDP and (d) urbanization levels in different administrative districts in the Pearl River Delta and surrounding areas, southern China (Fig. 1). 


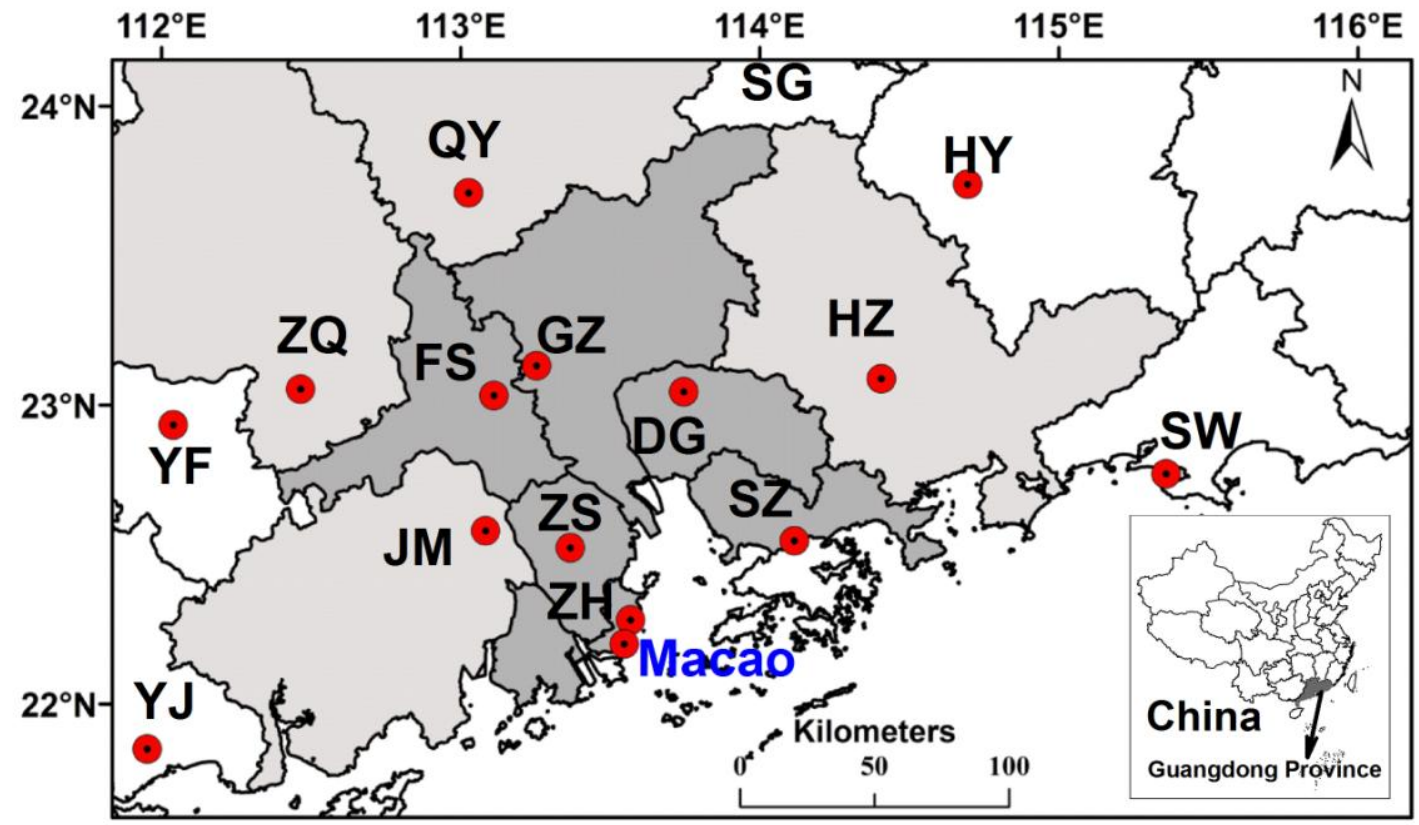

(a) Districts and regions of sampling region

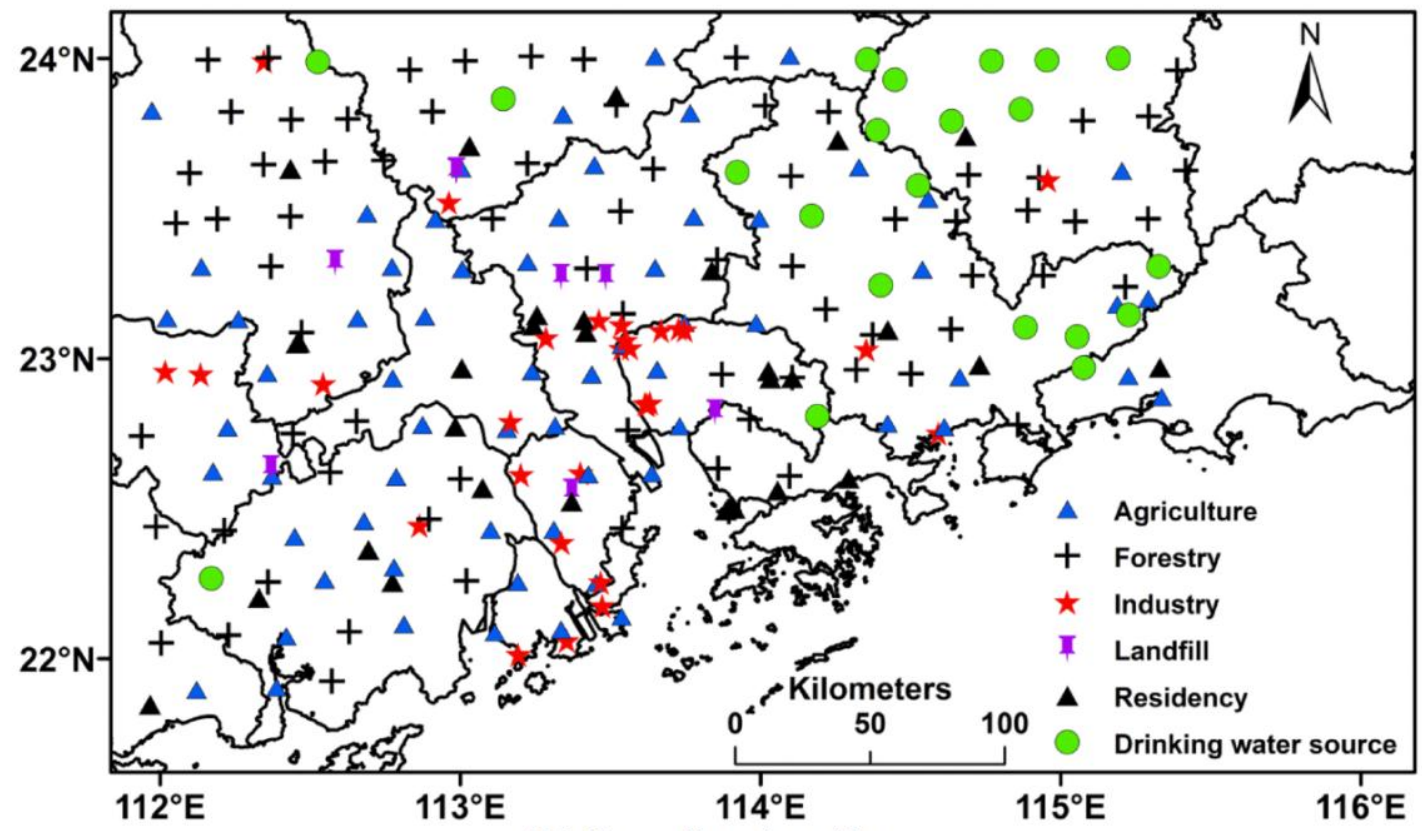

(b) Sampling location

Fig. 1 


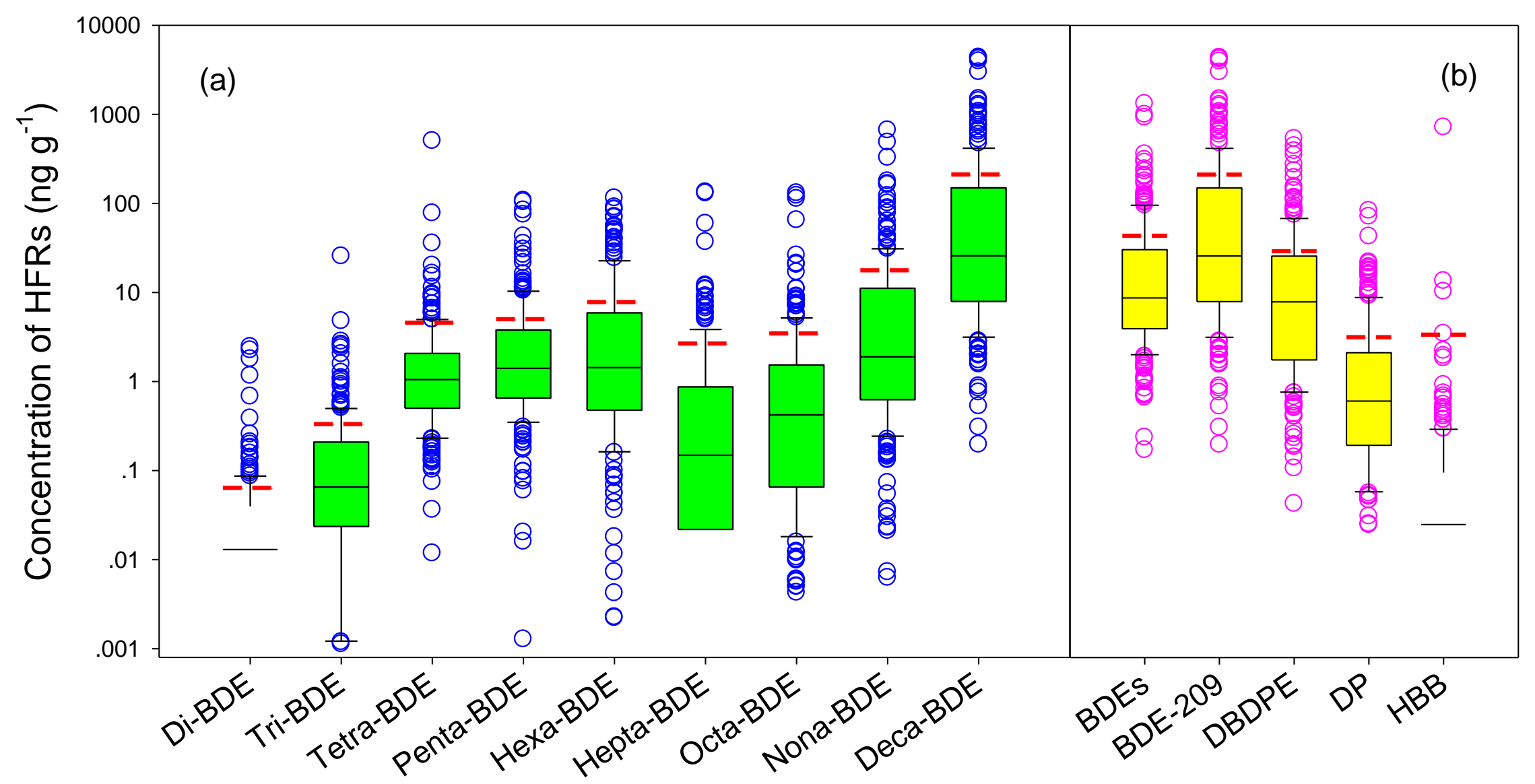

Fig.2 


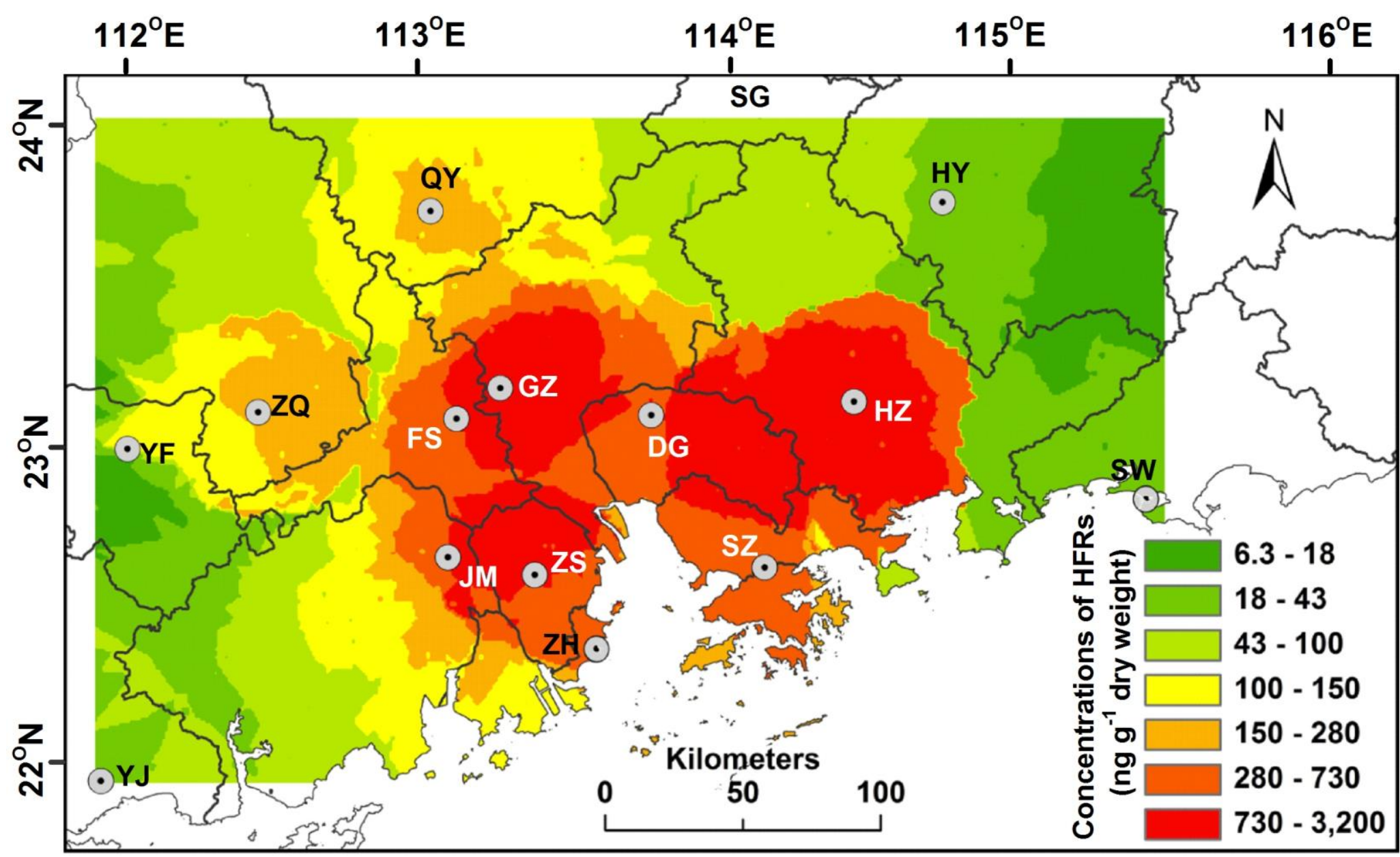

Fig. 3 

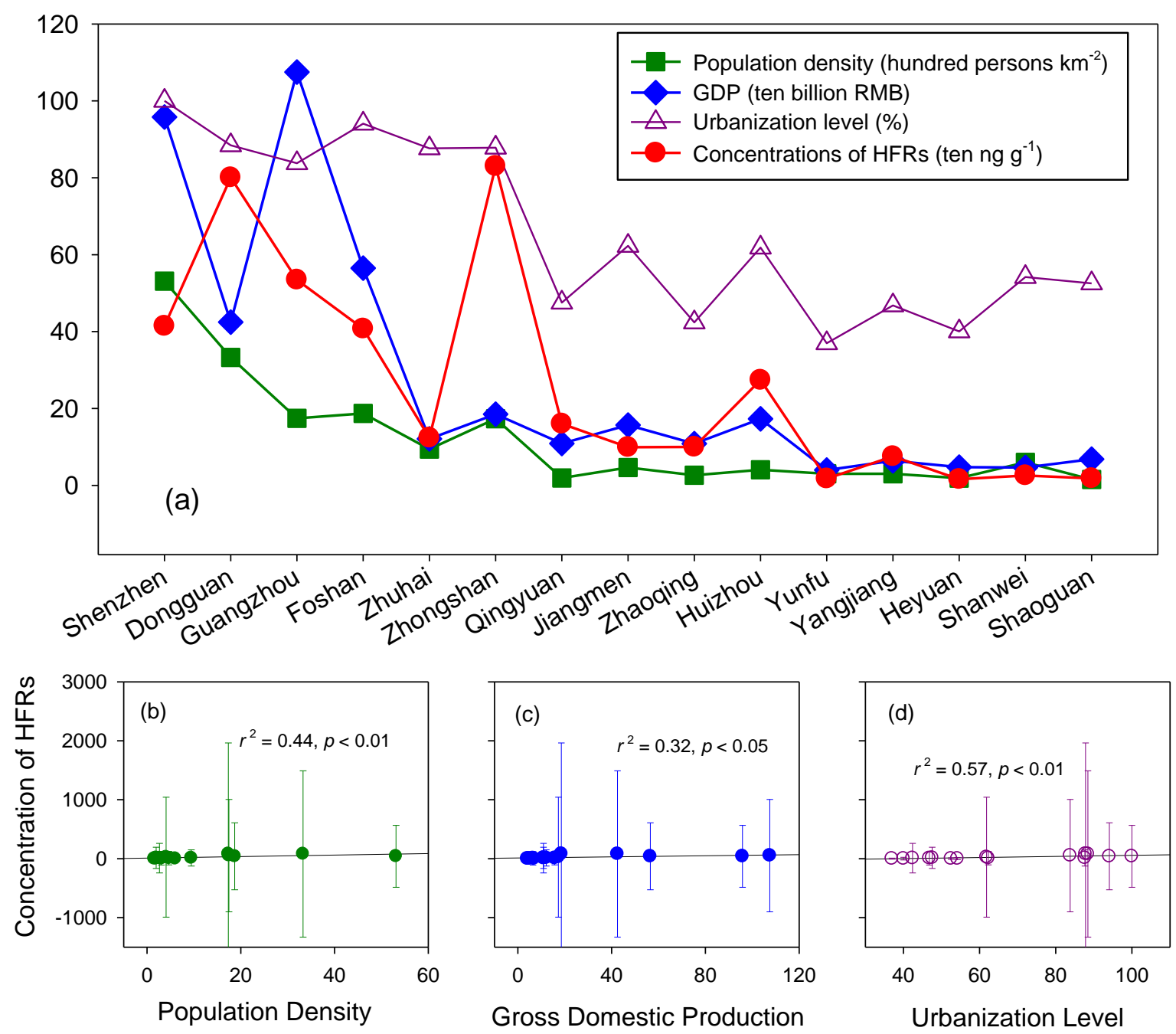

Fig. 4 